\title{
Scanning electron microscopic studies on tongue of open-nesting honey bees Apis dorsata F. and Apis florea F. (Hymenoptera: Apidae)
}

\author{
Neelima R. Kumar, Kalpna Nayyar, Ruchi Sharma and Anudeep* \\ Department of Zoology, Panjab University, Chandigarh-160014, INDIA \\ *Corresponding author: anuresearch_aedes@yahoo.com \\ Received: December 3, 2014; Revised received: March 3, 2015; Accepted: April 24, 2015
}

\begin{abstract}
Taste stimuli play vital role in the life of honey bees. Sensory structures observed on tongue of the honey bees with the help of Scanning electron microscopy (SEM) have become an important tool in analyzing honey bee biodiversity which offers an advanced diagnostic tool to study honey bee biogeography and determine adaptive variations to native flora. Tongue of honey bees present a high geographic variability in regard to the floral resources visited by the bees. The present study has determined to determine differences in the tongue of open-nesting bees by scanning electron microscopy of Apis dorsata and Apis florea. The two bees showed distinct morphological variations with respect to the lapping and sucking apparatus. It was observed that the ridges on the proximal region exhibited rough surface on A.dorsata whereas spinous in case of A.florea. Moreover, the arrangement of hair in the middle part of the tongue also differed in the two species. The shape of flabellum differed in the two species reason being the influence of native flora. It was observed that the shape of flabellum was oval in A.dorsata whereas in A.florea it was triangular. These differences indicated for the role of native flora and honey bee biodiversity.
\end{abstract}

Keywords: Apis dorsata, Apis florea, Scanning electron microscopy (SEM), Tongue

\section{INTRODUCTION}

The mouth parts of honey bee are adapted for chewing -lapping. They consist of paired mandibles or jaws attached on the sides of the head and proboscis or tongue, made up of the maxillae and the labium. The mandible and labium are of chewing type. Moreover, the mandibles are used in molding the wax. The maxillae and labium are developed into a series of flattened elongate structures to form a proboscis (Winston, 1987). The glossa of labium is greatly elongated, clothed with hair and terminates in a small rounded lobe, the flabellum forming a flexible spoon (Michener and Brooks, 1984). The tongue can be moved from side to side or withdrawn deeply into the head. It is deeply grooved on its posterior face from the flabellum to the base. Scanning electron microscopy (SEM) has been used to strengthen studies on biodiversity. Whitehead and Larsen (1976) used light and electron microscope to describe sensilla located on the mouth parts, antenna and distal segments of the forelegs. Kumar et al. (2014) performed SEM studies on tongue of cavity-nesting bees- $A$. cerana and $A$. mellifera and found significant differences in the spinous processes and the flabellum of the tongue. In the present investigations, SEM studies of the tongue of open-nesting species $A$. dorsata and $A$. florea were undertaken to illustrate their three regions- proximal region, middle region and flabellum.

\section{MATERIALS AND METHODS}

Study area and sample collection

Two open-nesting species- $A$. dorsata $\mathrm{F}$. and $A$. florea $\mathbf{F}$. were taken for the present study. $A$. dorsata was collected while foraging on flowers in Botanical garden, Panjab University, Chandigarh while $A$. florea was collected from nests located in hedges and bushes in Panjab University Campus.

\section{Scanning electron microscopy}

Preservation: The collected material of $A$. dorsata and A. florea was preserved in $70 \%$ alcohol and the protocol of Bozolla and Russell (1999) was followed.

Preparation of material for scanning electron microscopy: The tongue was carefully excised from the freshly collected worker bees of Apis florea and $A$. dorsata. These were then washed with phosphate buffer. The samples were fixed in 5\% gluteraldehyde for 2 hrs. Subsequently these were washed with phosphate buffer 2 to 3 times and then dehydrated through graded series of acetone and dried in a critical point drier. Dehydrated samples were mounted on slides in the desired orientation with the help of double side adhesive tape under binocular microscope. The samples were attached in such a way that they became visible from all sides. The stubs were placed inside the sputter for gold coating to overcome the problem of "charging" and "beam damage". The sputtered specimens were examined in Jeol JS-6100 scanning electron microscope 
operated at an acceleration voltage of $10 \mathrm{KV}$ at Regional sophisticated instrumentation centre, Panjab University, Chandigarh. The results of scanning were preserved as photographs used in this presentation.

\section{RESULTS}

Apis dorsata : The tongue of honey bees showed 3 regions- proximal, middle grooved region and distal spoon shaped flabellum (Figs. 1 and 2).

Apis dorsata: The proximal region possessed distinct pattern of ridges bearing spinous structures which gave rough surface to this region. In $A$. dorsata, the middle part was grooved and possessed rows of spines along the groove showing uneven arrangement of spines around the sucking plate. The spines were broad at the base and pointed towards the tip (Fig. 3). The shape of the flabellum was oval in $A$. dorsata (Fig. 4). The distal end of flabellum was fringed with row of two types of branched processes. Majority of these were straight proximally and branched only at distal end. A few were much longer, bearing a regular series of lateral spinous structures (Figs. 4a and 4b).

Apis florea: The proximal region of $A$. florea was equipped with distinct pattern of ridges bearing spinous structures. In $A$. florea, the middle part was grooved and possessed rows of hair converging towards the centre. The arrangement of hair differed. Two rows

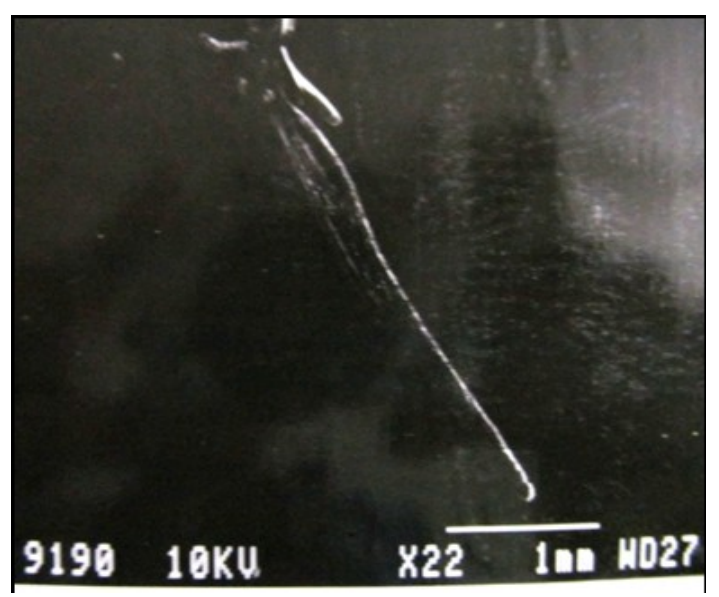

Fig. 1. Tongue of $A$. dorsata.

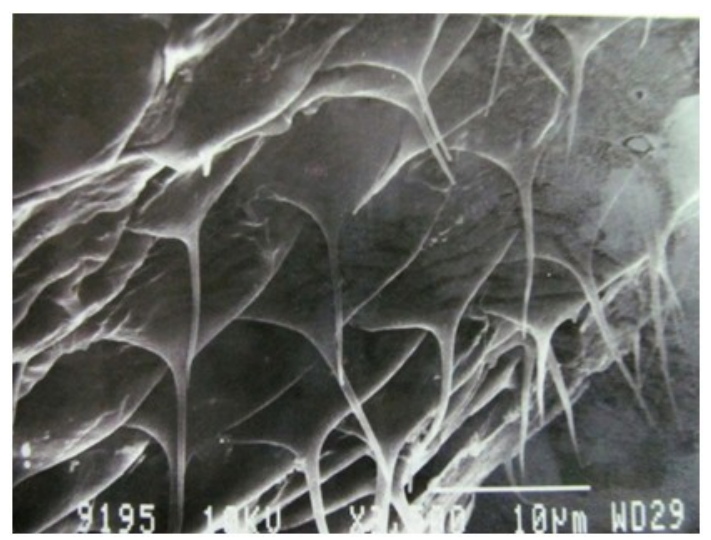

Fig. 3. Higher magnification of middle part of A.dorsata of hairs converged towards the center from margins. In the middle part, hairs were broad at the base with tapering end and a few also showed a small branch. The middle region showed sharp, spinous hair like structures. The hairs were broad at the base with tapering ends. Two rows of long unbranched hair converged towards the center forming sucking siphon (Fig. 5). The distal end was bearing the fluid absorbing organ i.e. the flabellum. It was triangular in shape. The margins of flabellum had processes which were further divided at their tips in a characteristic manner (Fig. 6).

\section{DISCUSSION}

Galic (1971) had studied the morphology of gustatory sensilla by using light microscopy. Whitehead and Larsen (1976) found that taste sensilla were present on the antenna, mouth parts, tarsus and pretarsus of the honey bee. Esslen and Kaissling (1976) performed SEM studies on A. mellifera L. and observed gustatory sensilla in the form of hair (chaetic sensilla) or pegs (basiconic sensilla). Erickson et al. (1986) performed the SEM studies on the mouth parts of worker $A$. mellifera. They reported the sensilla and their distribution on the labrum, mandibles and maxillae. Ultra structure of the tongue was found to be a useful tool in differentiating bee populations and as suggested by Mattu and Verma (1983 a, b), it is right to assume that this

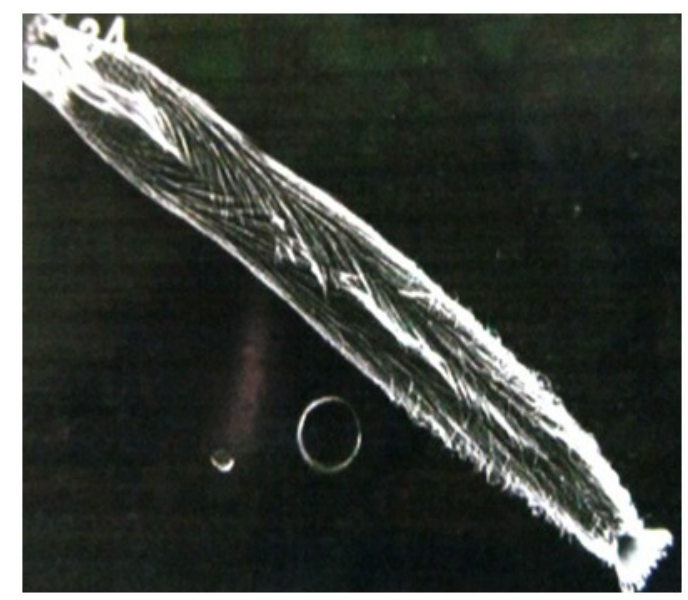

Fig 2. Tongue of A. florea $($ Bar $=100 \mu \mathrm{m})$.

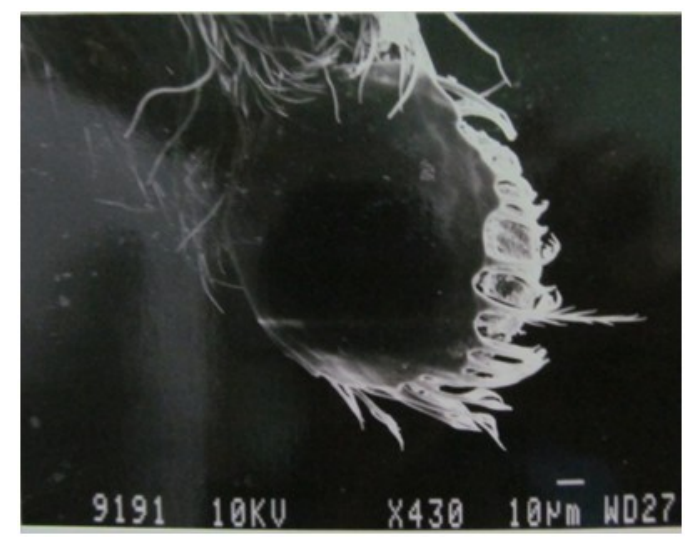

Fig.4. Flabellum of tongue of A. dorsata 


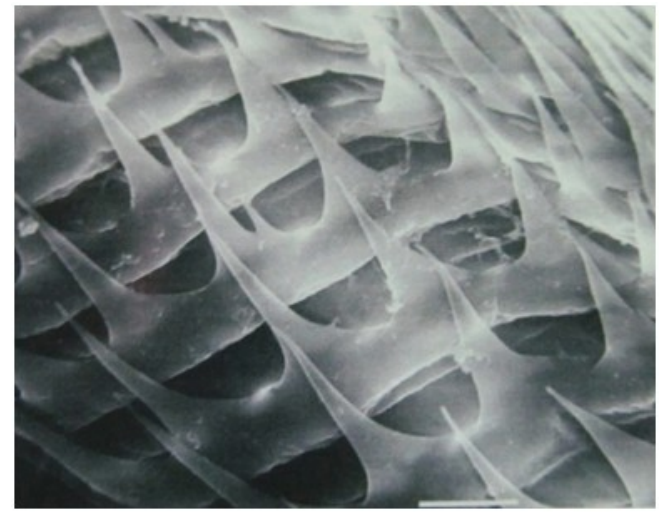

Fig. 5. Middle part showing groove and arrangement of long hair of A. florea (Bar= $10 \mu \mathrm{m})$.

ultramorphology is more influenced by the natural flora of a particular ecotype than with its physio-geographic parameters. The findings during the present investigations are interesting in order that basically in the two open-nesting species of Apis, ultrastructural differences were observed reflecting variation under the influence of native flora. The shape of the flabellum is responsible for the flora type and during the present work, the differences in the flabellum of two species support a high geographic variability related with the floral resources visited by the bees (Padilla et al., 2001). Earlier, differences in the shape of the sensory structures of tongue of $A$. dorsata F. from Nurpur and Jaipur have been reported by Anudeep and Kumar (2012). They reported different types of sensilla found on prementum, labial palps, galeae and glossa and attributed these to different environmental conditions. Kumar et al. (2014) performed SEM studies of mouthparts of cavity-nesting bees- $A$. mellifera and $A$. cerana and observed distinct morphological variations with respect to lapping and sucking apparatus. By comparing their work with the present observations, it was observed that similar pattern of ridges on the proximal region in $A$. dorsata and $A$. cerana. In $A$. dorsata, the middle part was grooved and possessed rows of spines the showing uneven arrangement of spines around the sucking plate. On the other hand, Kumar et al. (2014) observed that in case of A. cerana the middle region formed a sucking siphon. In the present work, the shape of the flabellum was oval in A. dorsata whereas Kumar et al. (2014) observed that the shape of the flabellum was rhomboidal in A. cerana.

Regarding the $A$. florea, in the present investigations, the proximal region of Aflorea was bearing distinct pattern of ridges possessing spinous structures. These observations were similar to that of $A$. mellifera by Kumar et al. (2014). In A. florea, the middle part was grooved and possessed rows of hair converging towards the centre. Two rows of long unbranched hair converged towards the center forming sucking siphon. This sucking siphon was somewhat similar to that of $A$. cerana observed by Kumar et al. (2014). In case of $A$. mellifera, Kumar et al. (2014) observed middle part which exhibited irregular arrangement of rows of hair

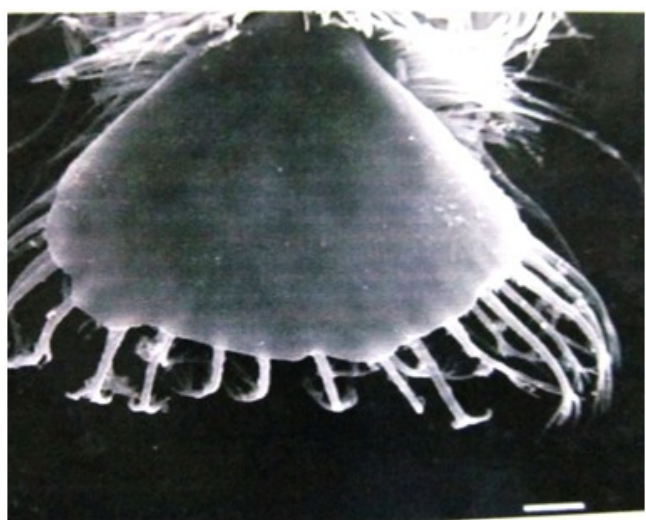

Fig. 6. Flabellum showing branched processes of A. florea (Bar= $10 \mu \mathrm{m})$.

along the grooved region. The distal end was bearing the fluid absorbing organ i.e. the flabellum. In the present investigations, the flabellum in A. florea was triangular in shape similar to that observed in A. mellifera by Kumar et al. (2014).

Striking differences were observed in the arrangement of hair in the middle region and the shape of flabellum of the two species viz., A. dorsata and A. florea which might be due to the native flora. By comparing the work of Kumar et al. (2014) with the present investigations, it was observed that the shape of the flabellum in case of $A$. mellifera and A. florea was similar and that of $A$. dorsata and $A$. cerana resembled each other.

\section{Conclusion}

The findings during the present investigations revealed that the proximal region of the tongue, the ridges in $A$. dorsata gave a rough surface whereas in $A$. florea the surface was spinous. Regarding the middle region, the arrangement of hair was different in the two species. The flabellum in $A$. dorsata was oval whereas in case of $A$. florea it was triangular. Therefore, these differences in the two species account for the variation under the influence of native flora. Present SEM studies helped to identify characteristic ultrastructural variations observed in the different parts of the tongue of the two open-nesting species.

\section{ACKNOWLEDGEMENTS}

We are grateful to UGC (BSR), F. 5-90/2007 (BSR) New Delhi for providing financial assistance to Zoology department, Panjab University, Chandigarh.

\section{REFERENCES}

Anudeep and Kumar, Neelima R. (2012). Biodiversity of Apis dorsata F.: Ultrastructure of the tongue. Geobios, 39 (4): 251-253.

Bozolla, J.J. and Russell, L.D. (1999). Electron Microscopy: principles and techniques for biologists.Second edition, Jones and Bartlett Publishers, Boston (USA), pp. 644.

Erickson, E.H., Carlson, Stanley D. and Garment, M.B. 
(1986). A scanning electron microscope atlas of the honey bee. Iowa state University Press, Ames, IA, pp. 292.

Esslen, J. and Kaissling, K.E. (1976). Zahl und Verteilung antennalar Sensillen bei der Honigbiene (Apis mellifera L.). Zoomorphologie, 83: 227-251.

Galic, M. (1971). Die Sinnesorgane an der Glossa dem Epipharynx und dem Hypopharynx de Arbeiterin von Apis mellifica L. (Insecta, Hymenoptera). Z. Morph. Okol. Tiere., 70: 201-228.

Kumar, Neelima R., Nayyar, K., and Anudeep (2014). Biodiversity in cavity-nesting honey bees Apis cerana F. and Apis mellifera L. (Hymenoptera: Apidae): Ultrastructure of mouth-parts. J.Global Biosc.,3 (4) :787-791.

Mattu, V.K. and Verma, L.R. (1984a). Morphometric studies on the Indian honey bee, Apis cerana indica F. Effect of seasonal variations. Apidologie, 15: 63-74.

Mattu, V.K. and Verma, L.R. (1984b). Comparative morphometric studies on the Indian honey bee of the North-West Himalayas. 3. Hind leg, tergites and sternites. J. Apic. Res., 23: 117-122.

Michener, C.D. and Brooks, R.W. (1984). Comparative study of the glossae of bees. Contrib. Amer. Entomol. Inst., 22: 1-73.

Padilla Alvarez, F., Valerio Da Silva, M.J., Campano Cabanes, F., Jimenez Vaquero, E., Flores Serrano, J.M., Puerta Puerta, F. and Bustos Ruiz, M. (2001). Discriminacion entre poblaciones de abejas (Apis mellifera L.) del suude Espana, Centro de Portugal of Madeira. Arch. Zootec., 50: 79-89.

Whitehead, A.T. and Larsen, J. (1976). Ultrastructure of the contact chemoreceptors of Apis mellifera (Hymenoptera, Apidae). Int. J. Insect. Morphol. Embryol., $5: 301-315$.

Winston, M.L. (1987). The Biology of the honey bee. Harvard University Press, Cambridge, Massachusetts, pp 281. 